\title{
Consolidation of the neural trace in memory: ECS-produced retrograde amnesia is not an artifact of conditioning
}

\author{
RICHARD A. KING ${ }^{1}$ \\ UNIVERSITY OF NORTH CAROLINA AT CHAPEL HILL
}

\begin{abstract}
A test was made, with a one-trial passive avoidance task, of two conditioning explanations of the amnesic effects of ECS. Results did not support the conditioning explanations: ECS alone had no effect upon latency; ECS was about equally effective as a disrupter of avoidance behavior when given in either the start box or the goal box; a gradient of decreasing effectiveness of ECS was obtained as the foot shock-ECS interval increased.
\end{abstract}

Many experiments have shown that a single electroconvulsive shock (ECS) given after a learning trial markedly modifes subsequent performance (see McGaugh \& Petrinovich, 1966). Such performance modifications due to a single ECS after learning are usually considered to be the result of disruption of memory consolidation by the ECS. Since an explanation in terms of consolidation, if correct, has wide reaching implications, it is important to make sure that other explanations of the posttrial ECS-produced performance effects are not likely in the one-trial situations best used to test the amnesic effects of ECS. Alternative explanations in terms of competing responses or conditioned inhibitory states produced by the ECS and conditioned cues in the test apparatus have been proposed (Adams \& Lewis, 1962a, b; Lewis \& Maher, 1965).

A test of conditioning explanations of ECS-produced retrograde amnesia (RA) is made in this experiment. Conditioning explanations require that a competing response or an inhibitory state be conditioned to cues present when the ECS is given. The test in this experiment is to give a single ECS in either the goal or start box of a two compartment, passive avoidance apparatus. ECS in the start box should, if competing responses or conditioned inhibition are factors, result in performance characterized by longer latencies than ECS given in the goal box. On the other hand, if consolidation disruption and RA result from ECS, start box latencies after ECS should not be longer than goal box latencies.

Another test of the conditioning theories of ECSproduced RA comes from the results of several groups of animals given ECS in the goal box. The consolidation explanation would predict that ECS would be less and less effective as the time interval between the learning trial and ECS is increased; the conditioning explanations would not predict such a graded effect of ECS if the ECS were always given in the apparatus where the subsequent test for ECS effects took place.

\section{Method}

Subjects were 148 male Wistar albino rats which were between 90 and 140 days old. They were run in a two compartment apparatus; the compartments were distinct and were separated by a sliding door which pulled out horizontally. The apparatus was covered by Plexiglas with a slot down the middle to allow free passage of the wires for giving ECS (see below).

Ss were put on a $23 \mathrm{~h}$ water deprivation schedule with food always available; this schedule was maintained, with the exception noted below, throughout the experiment. Next, all animals were anesthetized and wound clips for the attachment of alligator clip ECS electrodes were applied to the muscle and skin in a shaved area behind the ears. The next steps were adaptation and pretraining trials. Adaptation was given by placing the $S$ in the goal box with the electrodes and leads attached; such adaptation was given on five days. After the last of these adaptation trials, no water was given and the Ss were pretrained on the next day $47 \mathrm{~h}$ deprived. Pretraining was accomplished by putting Ss in the goal box until they drank for 10 sec; five such pretraining trials were given.

Training and testing occupied the next five days of the experiment. On each of the first three days of this period, the Ss were given five training trials. A training trial consisted of placing the $S$ in the starting compartment and reinforcing running to the goal box with a $10 \mathrm{sec}$ drink of water. On the fourth day of the training and testing period, the first trial was a regular training trial-Training Trial 16. While the $\mathrm{S}$ was drinking during this trial, foot shock was given, and then a $0.5 \mathrm{sec}, 60 \mathrm{~mA}$ ECS was given to those Ss receiving ECS. The following groups were run: (1) Foot shock only; (2) ECS only; (3) Foot shock-ECS interval of $5 \mathrm{sec}$ with ECS given in the start box; (4) Foot shock-ECS interval of $5 \mathrm{sec}$ with ECS given in the goal box; (5) Foot shock-ECS interval of $15 \mathrm{sec}$ with ECS given in the goal box; (6) Foot shock-ECS interval of $60 \mathrm{sec}$ with ECS given in the goal box; (7) Foot shock-ECS interval of $600 \mathrm{sec}$ with ECS given in the goal box; (8) Foot shock-ECS interval of $1800 \mathrm{sec}$ with ECS given in the goal box; (9) Foot shock-ECS interval of $3600 \mathrm{sec}$ with ECS given in the goal box.

On test trials, 22-24 $\mathrm{h}$ after treatment administration, Ss were put into the start box and allowed to run to the goal box to drink water. As in training, latencies were measured; passive avoidance induced by the single foot shock was indicated by long latencies, 
Table 1. Training and Test Latencies Median Latency $(\mathrm{Sec})$

( $\mathrm{N}$ in parentheses) Training Trials

(Trials 13-15) Test Trials

(Trials 17-19)

\begin{tabular}{|c|c|c|c|}
\hline \multicolumn{4}{|c|}{ Footshock-ECS Intervals: } \\
\hline $5 \mathrm{sec}$, ECS start box & $(10)$ & 1.31 & 1.85 \\
\hline b5 sec, ECS goal box & (25) & 1.43 & 1.99 \\
\hline $\mathrm{ab} 15 \mathrm{sec}$ & (14) & 1.13 & 1.97 \\
\hline$c_{60 \mathrm{sec}}$ & (10) & 1.24 & 6.87 \\
\hline$c_{600 \mathrm{sec}}$ & (10) & 1.19 & 2.92 \\
\hline$c_{1800 \mathrm{sec}}$ & (10) & 1.29 & 16.84 \\
\hline$c_{3600 \mathrm{sec}}$ & (15) & 1.30 & 32.00 \\
\hline \multicolumn{4}{|l|}{ Control: } \\
\hline${ }^{{ }^{C} \text { Foot shock only }}$ & (34) & 1.49 & 54.70 \\
\hline ECS only & $(20)$ & 1.20 & 1.34 \\
\hline
\end{tabular}

$a_{E C S}$ given in goal box for all except 5 sec, ECS start box group $b_{\text {Difference between training trials and test trials significant: } .01<\boldsymbol{P}<05}$

${ }^{c_{D i f f e r e n c e}}$ between training trials and test trials significant: $P<01$

while failure of passive avoidance was indicated by short latencies. Three such test trials, separated from each other by about $15 \mathrm{~min}$, were given each $\mathrm{S}$ on the testing day. The median latency on these three test trials is the test score for each $\mathrm{S}$.

\section{Results and Discussion}

The results, in terms of median latencies on Training Trials 13-15 and the three test trials, are shown in Table 1. The procedure generated a fairly stable baseline from which the effects of treatments could be evaluated; this is shown in the results for Training Trials 13-15. Baseline scores were compared with test scores by the Wilcoxon matched-pairs, signedranks test (Siegel, 1956). Evaluation of control group results indicated that foot shock by itself produced passive avoidance and that ECS alone produced no effect on latency.

Evaluation of the results of the experimental groups with pairings of foot shock and ECS indicated no effect of the foot shock for the $5 \mathrm{sec}$ foot shock-ECS group when the ECS was given in the start box. A 5 sec foot shock-ECS interval when ECS was given in the goal box increased latency slightly. All other foot shock-ECS intervals also show that the effects of foot shock have not been completely obliterated by ECS. The effectiveness of ECS is greatest at the shorter intervals and this might be interpreted as being congruent with a consolidation hypothesis. Analysis of the test trial scores by the Mann-Whitney $U$ test (Siegel, 1956) indicated that all except the 1800 and $3600 \mathrm{sec}$ groups had significantly shorter latencies than the foot shock only control group $(p<.01$ in all significant cases). Thus ECS had some effectiveness up to $600 \mathrm{sec}$ after the foot shock in this experiment; however, because of the reinforcement for short latencies, this experiment was not designed to measure the consolidation period accurately.

The present experiment provides no support for the conditioning explanations of the effectiveness of ECS. First, in contrast with other experiments in which ECS electrodes were attached directly to the ears (e.g.. King, 1965), a single ECS in the goal box had, by itself, no effect on performance. Second, goal box and start box ECSs were about equally effective as disruptors of passive avoidance. Finally, the gradient of effect of ECS with increasing foot shock-ECS intervals would seem to be predicted by the consolidation hypothesis but not by the conditioning hypotheses.

\section{References}

ADAMS, H. E., \& LEWIS, D. J. Electroconvulsive shock, retrograde amnesia, and competing responses. J. comp. physiol. Psychol., 1962a, 55, 299-301.

ADAMS, H. E., \& LEWIS, D. J. Retrograde amnesia and competing responses. J. comp. physiol. Psychol, 1962b, 55, 302-305.

KING, R. A. Consolidation of the neural trace in memory: Investigation with one-trial avoidance conditioning and ECS. J. comp. physiol. Psychol, 1965, 59, 283-284.

LEWIS, D. J., \& MAHER, B. A. Neural consolidation and electroconvulsive shock. Psychol Rev., 1965, 72, 225-239.

McGAUGH, J. L., \& PETRINOVICH, L. L. Neural consolidation and electroconvulsive shock reexamined. Psychol. Rev., 1966, 382-387. SIEGEL, S. Nonparametric Statistics. New York: McGraw-Hill, 1956. Note

1. Experiment done while the author was a Special Post-doctoral Fellow in the Department of Physiology and Biophysics at the University of Washington, Seattle, Washington. Supported by NINDB Grant No. F11 NB 1127-02. 